\title{
INNOVATIONS OF A GREEN PRODUCT
}

\author{
Denisa Mala $^{1, a, *}$ and Dana Bencikova ${ }^{2, b}$ \\ ${ }^{1}$ Faculty of Economics Matej Bel University in Banská Bystrica, Department of Corporate Economics \\ and Management, Tajovského 40, 97590 Banská Bystrica, Slovakia \\ ${ }^{2}$ Faculty of Economics Matej Bel University in Banská Bystrica, Department of Language \\ communication in Business, Tajovského 40, 97590 Banská Bystrica, Slovakia \\ adenisa.mala@umb.sk, bdana.bencikova@umb.sk \\ *Corresponding author
}

Cite as: Mala, D., Bencikova, D. (2018). Innovations of a green product, Ekonomicko-manazerske spektrum, 12(1), 64-74.

Available at: dx.doi.org/10.26552/ems.2018.1.64-74

\begin{abstract}
These days, differentiating and ecologizing of the products has been gaining more and more importance. Therefore, green logistics has earned its indisputable position in an enterprise, as an important tool ensuring competitiveness. Small and medium enterprises may achieve these goals by implementing green innovations into a product as well as into the processes in an enterprise. The main objective of this paper is to propose possibilities of implementing green innovations of products and processes in Slovak small and medium enterprises. A survey which has been carried out regarding this topic, focused on the analysis of the perception of green products by customers, and on identifying the factors which customers take into consideration when making purchase decisions related to these products. The research has been evaluated by methods of testing the statistical hypothesis (Chi-square test, Friedman test, and the Wilcoxon test), methods of descriptive statistics, and data visualization. The conducted survey revealed that one of the main reasons why customers of Slovak small and medium enterprises do not buy green wooden products is their high price and lack of information related to them. When making purchases, our respondents also take quality and safety of green products into account. Based on the results of our research, the individual steps in the process of implementing green product innovations in an enterprise were proposed for Slovak small and medium enterprises. It is suggested that SMEs should place emphasis on responsible approach to the environment, long-term effort to make their operations sustainable, and providing green products in order to achieve smooth implementation of green innovations into their operations.
\end{abstract}

Keywords: green product, innovation, strategy

JEL Classification: M11, M19, M21

\section{Introduction}

Within strategic direction of successful enterprises, orientation towards customer's requirements is inevitable, along with the need to supply the goods in time and to a right place (Faletar et al., 2016). Differentiation and ecologization of products are, therefore, greatly rising in their importance, argue by Hajduchova et al. (2016). Successful enterprises respond flexibly to customer requirements, and remain profitable in the market thanks to implementing the environmental needs as soon as in the process of planning production and developing the product, according to Mala \& Musova (2015), Sedliacikova et al. (2016). 
There are several classifications of green products. Green products may be classified on the basis of the product characteristics, according to Dangelico \& Portrandorfo (2010), by the extent to which to the product affects the environment, stated by Hanssen (1999), or based on the type of the strategy chosen to improve the environment, argue by Rosa \& Devashish (2010). Kaebernick \& Soriano (2000) use a simplified approach of classifying green products by ranking products among different groups according to their environmental functions. This classification is based on the four phases of the product life cycle (material, process, use, and disposal), while the authors divide products into two group as follows: according to the used material, and according to energy consumption. Sousa \& Wallace (2006) developed an automated system of classification based on the identification of groups of products according to environmental categories. Roy et al. (1996) classified the impact of products on the environment by two dimensions: the main phases of the life cycle (production, use, and disposal), and the environmental aspects of the product (energy consumption, used material / resources, level of pollution, and toxicity). Peattie's classification (1995) of green products is based on their ecological performance (products are labeled with different shades of the green color) and the type of a product (absolutely green and relatively green). Absolutely green products contribute to the improvement of the society and the environment, and relatively green products reduce their negative impact on the society and the environment.

It is essential to realize that each product affects the environment somehow. Therefore, it should be clearly identified when, why, and how much a product is green.

'When' means that it is necessary to identify that phase of the life-cycle during which the green characteristics of the product are expressed. We distinguish three main phases of a product life-cycle: before its use (focusing on material, production process, and transportation process), during, and after its use (the end of its life-cycle).

'Why' stands for the reasons why the product is considered green. We determine the effect of the green product on the environment, and the ways of its improvement, while emphasizing the used materials, energies, or the pollution, stated by Unruh \& Ettensin (2010).

'How much' identifies the type of influence a product has on the environment. A product is green if its effect on the environment is less negative, neutral, or positive when compared to common products, stated by Dangelico \& Pontrandolfo (2010).

In our opinion, evaluation of the product's effect on the environment must be performed with emphasis on the specific phase of its life cycle rather than from the point of view of the life cycle as a whole, because the product does not have a positive impact on the environment in every phase of its life cycle.

From the above said, we can conclude that a product is considered environmentally friendly if it is biologically degradable, which means that it does not represent any harm to the environment in case some substances may be released to the air, water, or soil during its use or disposal. These products normally decompose faster. An example of a biodegradable green product may be cleaning supplies, soap, or washing detergents. If a product contains any amount of recycled materials, it is also considered green. On one hand, recycling enables reuse of those materials which would otherwise end up at a garbage dump, and on the other hand, it is friendly to the environment, since the used materials do not have to be produced again. Products which have a significantly lower need of packaging materials can, in comparison with common products, also be considered green, as they require smaller transportation space, which consequently leads to reduced carbon emissions. If products have been made in a specially adjusted production process that saves energy, reduces carbon emissions, or uses renewable sources of energy, they can also be labeled as green. In this case a product should be environmentally friendly, but in reality, it is not always so. Progress has 
been achieved in the organization of production processes as well, and in such way which optimizes the production process, reduces its negative impact on the environment, and produces green products which do not represent harm or burden for the environment when used or disposed of. Each effort helps in reducing the negative impact of products on our environment.

\section{Methodology}

The research methodology consisted of three phases. In the first phase, methods of summary, synthesis, and analysis were used, and a short review was prepared. In the second phase, a questionnaire was administered to generate empirical data on a sample of adults Slovaks. To evaluate the results of the research, the statistical program IBM SPSS Statistics 19 was used. In the third phase, a process of implementing innovations of green products in Slovak SMEs will be proposed.

The primary data were collected through a questionnaire, which consisted of two parts. The first part of the questionnaire focused on identifying the respondents (by sex, age, job status, the achieved education, and net monthly income). The second part of the questionnaire consisted of five questions, and aimed at finding out how respondents in Slovakia perceive the green product and what affects their purchasing decisions. The first question focused on the level of agreement with the statements defining the green product. It was evaluated by the Likert scale, where 1 means high agreement and 4 means high disagreement. The second question focused on identifying those factors which respondents consider when making purchase decisions. The choices were the following: 1 -always consider, 2 - often consider, 3 - rarely consider, and 4 - never consider. The third question asked how often respondents buy the selected green products $(1-$ always, I actively search green products, 2 - when they are available, 3 - once in a year, 4 - once in 6 months, 5 - once in a month, 6 - once in a week, 7 - occasionally, when needed, 8 - never, 9 - I don't know such products). Questions 4 and 5 asked about the reasons why respondents buy, or do not buy, green products. The three most important factors could be chosen.

It was 675 respondents who participated in our research dealing with perception of a green product. For the research purposes, and to ensure the representativeness of the sample, 350 correctly filled-in questionnaire were used. The representativeness of the sample according to chosen criteria - sex, age, and achieved level of education, were tested by Chi-square test. In all cases, representativeness has been confirmed ( $\mathrm{p}$-value_sex $=0.983$, p-value_age $=1.0, \mathrm{p}$ value_achieved_education $=0.994$ ).

The survey data were evaluated based on descriptive, graphical, and statistical analyses. When evaluating the research results, the following methods of testing statistical hypotheses were used: Chi-squared, Friedman test, Wilcoxon test, methods of descriptive statistics, and data visualization (mean, modus, median, skewness, and frequency tables).

\section{Results}

The object of the research is a green product. The subject is adult inhabitants of Slovakia. For the purpose of the research, and in order to achieve the representativeness of the sample, 350 correctly filled-in questionnaires were used. The sample consisted of 171 male and 179 female respondents, most of them being between 35-44 (20\%) and over 65 years of age (17.7 $\%)$. Least respondents fell into categories between 18-24 (10.6\%) and 45-54 years of age $(16.3 \%)$. Most respondents (64.6\%) have achieved the secondary education, $28.3 \%$ without 
the graduation certificate, and $36.3 \%$ with the graduation certificate. The lowest percentage of respondents achieved the master's degree $(16 \%)$ and the doctoral degree $(1.1 \%)$. The majority of respondents (question 3) are full-time employees (54.6\%), sole traders $(13.7 \%)$, and retired $17.1 \%$. The smallest groups of respondents were housewives/househusbands $(0.3$ $\%)$, fully disabled $(1.1 \%)$, and unemployed $(1.4 \%)$. As to the net monthly income (question 5 ), the majority of respondents claim the income between $€ 20-400$ (22\%), and $€ 401-600$ $(24.9 \%)$. The least respondents fall into the income groups over $€ 1,500$ (3.1\%) and below $€ 200$ (4.9\%). The majority of respondents (76.9\%) earn between $€ 201$ and 1,000.

At present, enterprises use different terms to label/name products the impact of which on the environment is low, e.g. green, ecological, environmental, or sustainable product, etc. Question 1 aimed at finding out what respondents understand under the term green product. Respondents were given fifteen statements - definitions of what a green product is. They were further asked to indicate the degree of their agreement with each statement on a Likert scale 1-5. The results are presented in Figure 1.

Figure 1: The respondents' view of a green product

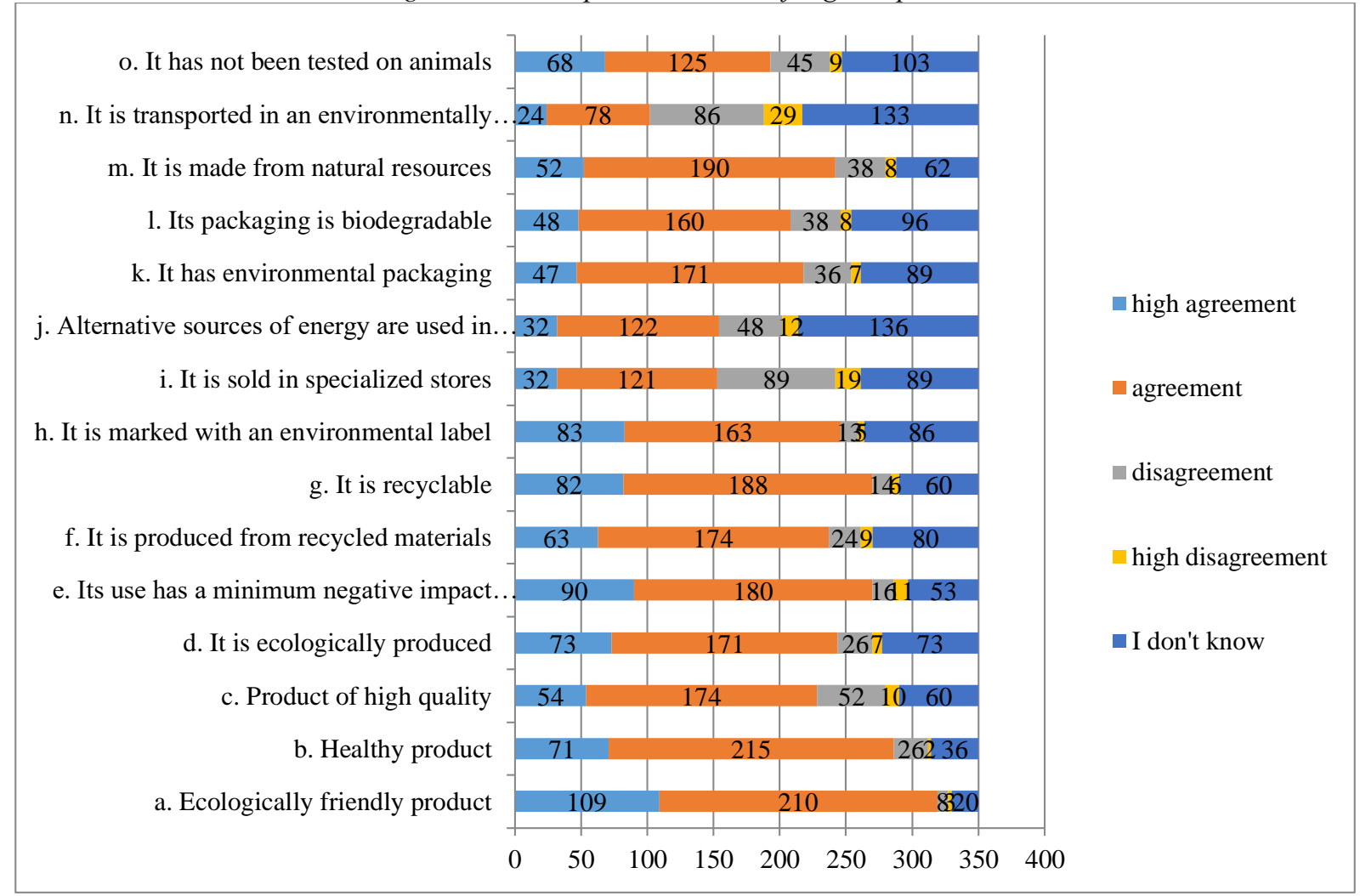

Source: Authors, based on the IBM SPPS 19 outcome

After evaluating the frequency of answers to the given question, we may claim that the majority of respondents expressed agreement with the statement that 'green product is environmentally friendly' (319 respondents) and 'it is a healthy product' ( 286 respondents). Least agreement was noted with green product being defined as 'a product of high quality' (62 respondents), sold in specialized stores (108 respondents), and transported ecologically (115 respondents).

Question 2 asked about the factors which customers consider when deciding to buy a green product. Figure 2 shows responses to this question from the frequency point of view. 
Figure 2: Factors which customers consider when buying a green product

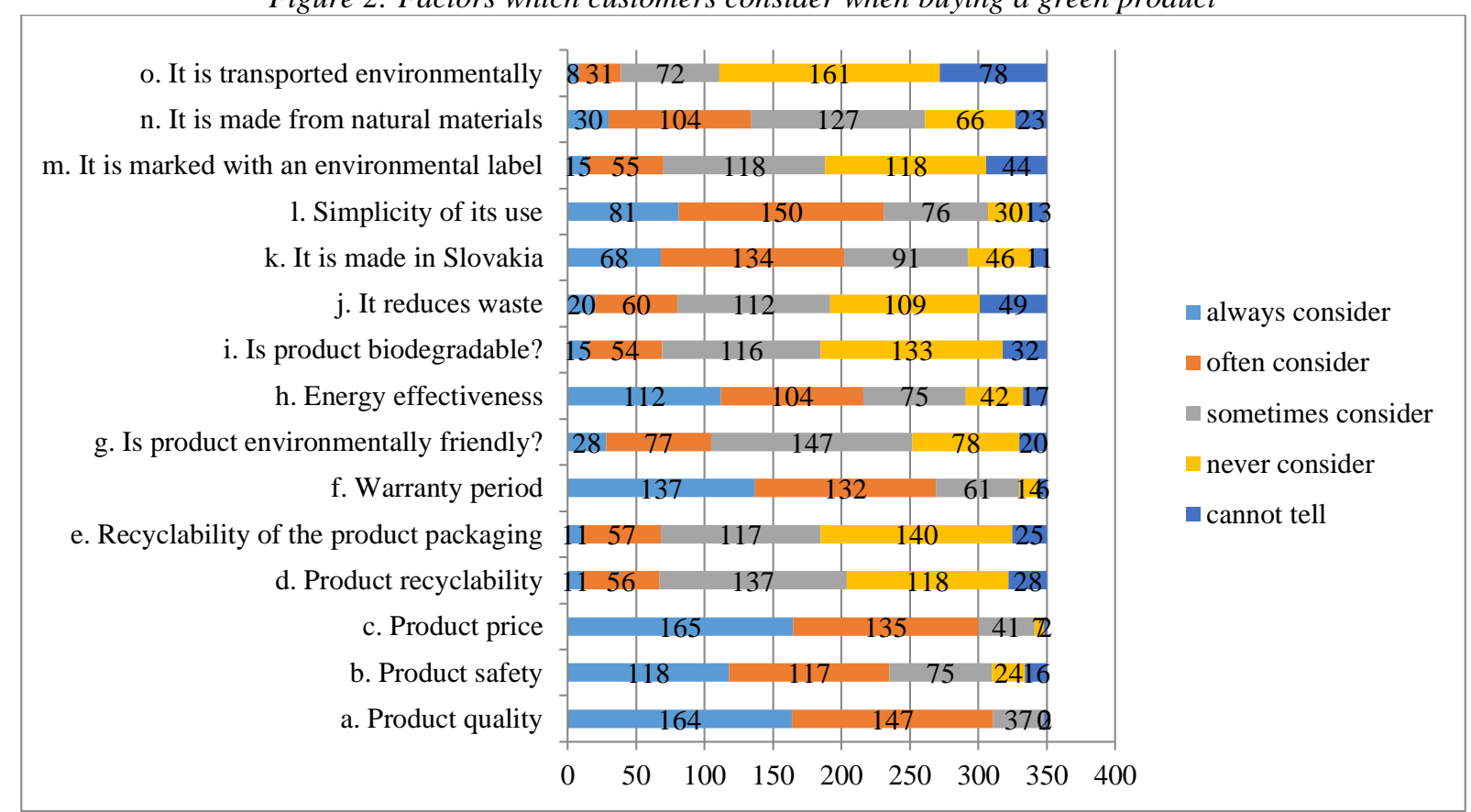

Source: Authors, based on the IBM SPPS 19 outcome

Considering the frequency of responses, we may claim that customers always consider the price and the quality of the product when making purchasing decisions. Friedman test has confirmed that the significance of these two options is not the same $(p$-value $=0)$. Subsequently, the Wilcoxon sign-rank test was used to determine the order of significance of the individual statements. Slovaks mostly consider the quality and the price of a product, which is followed by its safety, length of the warranty period, energy efficiency, and the simplicity of the product use. The least considered factors are: biodegradability of the product, environmental label, and recyclability of the product packaging. The last factor in the order of frequency of consideration is the environmental transport of the product.

Question 3 focused on the frequency of purchasing the individual types of green products (Table 1). For all types of a green product, the most frequent response was 'I buy it occasionally, i.e. when needed.

Table 1: Frequency of buying green products

\begin{tabular}{|c|c|c|c|c|c|c|c|c|c|}
\hline & 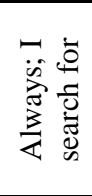 & 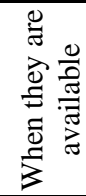 & 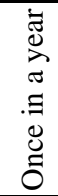 & 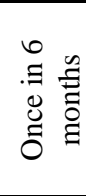 & 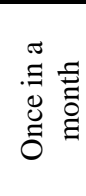 & 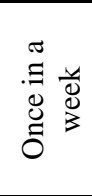 & 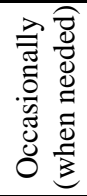 & $\frac{\dot{0}}{\dot{0}}$ & 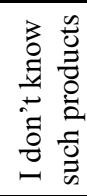 \\
\hline a. Bio-food (e.g. filtered water) & 41 & 84 & 29 & 22 & 17 & 16 & 111 & 25 & 5 \\
\hline b. "Fair trade" products (e.g. coffee) & 18 & 46 & 33 & 26 & 19 & 8 & 119 & 36 & 45 \\
\hline $\begin{array}{l}\text { c. Product with ecological packaging (e.g. } \\
\text { compostable packaging) }\end{array}$ & 6 & 43 & 44 & 27 & 14 & 6 & 122 & 60 & 28 \\
\hline $\begin{array}{l}\text { d. Products from local (Slovak) farmers } \\
\text { (cheese, milk, meat) }\end{array}$ & 82 & 89 & 16 & 22 & 29 & 24 & 70 & 15 & 3 \\
\hline $\begin{array}{l}\text { e. Products from ecological breeds (eggs } \\
\text { from deep litter system breeds, meat from } \\
\text { free-grazing animals, etc.) }\end{array}$ & 73 & 92 & 14 & 22 & 23 & 25 & 72 & 23 & 6 \\
\hline $\begin{array}{l}\text { f. Products that have not been tested on } \\
\text { animals (e.g. cosmetics) }\end{array}$ & 37 & 53 & 30 & 29 & 17 & 3 & 114 & 41 & 26 \\
\hline
\end{tabular}




\begin{tabular}{|c|c|c|c|c|c|c|c|c|c|c|}
\hline & $\begin{array}{l}\text { Recyclable products (e.g. papers, kitchen } \\
\text { towels, etc.) }\end{array}$ & 38 & 71 & 17 & 36 & 37 & 24 & 100 & 22 & 5 \\
\hline & $\begin{array}{l}\text { Non-toxic products (e.g. cleaning } \\
\text { detergents, cosmetics) }\end{array}$ & 25 & 65 & 27 & 26 & 37 & 7 & 107 & 37 & 19 \\
\hline i. & $\begin{array}{l}\text { Products made from natural materials (e.g. } \\
\text { shoes, clothes, etc.) }\end{array}$ & 30 & 59 & 36 & 42 & 18 & 5 & 115 & 28 & 17 \\
\hline $\mathrm{j}$. & $\begin{array}{l}\text { Energy-efficient products (e.g. washing } \\
\text { machine, light bulbs, etc.) }\end{array}$ & 72 & 45 & 34 & 7 & 11 & 7 & 152 & 13 & 9 \\
\hline $\mathrm{k}$. & $\begin{array}{l}\text { Biologically degradable products (e.g. } \\
\text { garbage bags, diapers, toilet paper, } \\
\text { shopping bags, etc.) }\end{array}$ & 24 & 56 & 29 & 27 & 26 & 19 & 111 & 38 & 20 \\
\hline 1. & $\begin{array}{l}\text { Products that do not harm the environment } \\
\text { (e.g. natural cleaning detergents, } \\
\text { ecological washing power, etc.) }\end{array}$ & 31 & 52 & 25 & 27 & 23 & 7 & 118 & 41 & 26 \\
\hline
\end{tabular}

Another interesting finding was that customers buy the majority of green products only occasionally. It was only the products from the local (Slovak) farmers and products from ecological breeds that are bought when they are available. This may be considered a proof of supporting local farmers and markets.

Question 4 asked why respondents buy green products, while they were instructed to indicate up to three options. Friedman test has confirmed that the given reasons are not of the same significance $(\mathrm{p}$-value $=0)$. Using Wilcoxon sign-rank test enabled us to determine the order of significance of the individual reasons.

Most frequently indicated reasons to buy green products were: their positive influence on the respondents' health, high quality, and a good feeling. These were followed by the product good reputation, caring for health of the respondents' close relatives, leading a healthy lifestyle, product's good price, product's high efficiency (e.g. energy efficiency), and persuasive advertising. The next responses in order of frequency were: ecological packaging, saving respondents' money, and good design of green products. The least frequently indicated reasons to buy a green product were: improving one's own image, saving time, and being available. It was 69 times that respondents indicated that they never buy green products. Interesting responses were also provided within the answer 'other', where 14 respondents indicated that they did not know why they buy green products, and 37 said they supported local farmers.

Other researches, e.g. Eze (2013), and Welsch \& Kuhling (2009) confirmed positive dependence between the purchase of green products and the social status of a customer. The individual behavioral norms also greatly affect the purchase of green products, according to Gadenne et. al. (2013), Smith \& Paladino (2010), Salazar (2013). Very often, customers prefer the functionality of a product, which satisfies their needs, to its esthetic aspects, according to Chen \& Lobo (2012). Quality and the positive effect of green products on the customer's health are also aspects that customers prefer when buying them, stated by Chan \& Wong (2012).

Question 5 verified why respondents do not buy green products. Respondents were asked to indicate maximum of three options. Friedman test has confirmed that the given reasons are not of the same significance ( $\mathrm{p}$-value $=0$ ). Wilcoxon sign-rank test enabled us to determine the order of importance of the individual reasons.

Clearly, the most frequently indicated reason for not buying green products was their high price. Other frequently chosen responses were: little information about green products, and their low availability in the market, followed by the responses 'I am not sure about their quality', and 'There are no advantages for me'. The least frequently indicated responses were the lack of trust for green products, and their unsuitability for daily use. 
Different authors Miles \& Covin (2000), and Fraj-Andres \& Martinez-Salinas (2007) have found out within their research that when an enterprise invests in green activities and in development of a green product, it achieves an effective use of disponsible resources, fast return on investments, increase in sales, improvement in the image of an enterprise, differentiation of its product from competitors, and easier penetration into new markets.

\section{Discussion}

Various authors, e.g. Miles \& Covin (2000), Pujari et al. (2003), Shrivastava (1995), Hajduchova et al. (2016), as well as the results of our research have confirmed that growth in the efficient use of disponsible resources in an enterprise, fast return on investments, improving the image of an enterprise, differentiation of an enterprise, and achieving a competitive advantage are significant benefits of the environmental sustainability within the development of green products and logistics activities. Within their research, Chen et al. (2006) have proved a direct dependence between the innovations of a green product and the green innovations of processes in an enterprise. The research of Dangelico \& Pujari (2010) has found out that the expected increase in the profit and the market share, along with the improvement of the enterprise's image, are the essential triggers of green innovations in an enterprise.

In our opinion, the following should be among the main steps leading to implementation of green innovations of a product in an enterprise: determining a strategy, proposing processes and designing a green product, carrying out the proposed processes, and evaluating the green product.

The first step is to determine the environmental policy and goals of an enterprise. Within an enterprise, it is the management who is responsible for setting the goals, while it should try to avoid compromising on quality of the product in relation to its green advantages. At the same time, the involvement of all employees in an enterprise should be ensured. The essential factors are gathering the information and knowledge in the area of legislation, results of scientific researches, and an effort to acquire information from those enterprises which are already providing green products. Lanzavecchia (2004) claims that at present, the only way of producing a green product is to adopt changes as soon as at the very beginning of the green product development, by selecting a new sales strategy aimed not only at optimizing the whole life cycle of the product with the focus on the environment, but also at optimizing the efficiency of the given product. From the customers' point of view, one of the main goals should be reducing the material demandingness, according to Klementova et al. (2016).

This step is followed by proposing the processes and the design of a green product. An enterprise looks for possibilities to improve the product from the environmental point of view. We incline towards the statement of Ottman et al. (2006) who claim that a product which has no negative impact on the environment does not exist. One of the main goals could be achieving the energy efficiency of products through development of alternative sources of energy. Out of 350 respondents, 112 indicated that they always take energy efficiency of a product into consideration, and 104 do it often. We think that it is necessary for the enterprises to aim the development of their products towards the reduction of their energy efficiency, or towards the future use of alternative sources of energy of the product.

The following step is material efficiency. Within our research, 134 respondents indicated that they always (often, respectively) consider the fact that a product is made of natural resources when purchasing it, 68 respondents expressed the same for the recyclability of packaging, and 67 for the recyclability of the product itself. We have found out that as many 
as 269 respondents always, or often, take the product warranty into consideration when purchasing it. Research of Polonsky \& Ottman (1998) has also proved that reducing the material demandingness is one of the basic characteristics of a green product. One way how to extend the warranty of a product is to choose the right materials. When attempting to fulfill this goal, an enterprise should actively search for suitable suppliers for the input materials (the best are those suppliers who are environmentally friendly), and ensure availability of sustainable materials. Product development must be directed towards reduction of its size and weight, use of biodegradable materials and materials from renewable sources, recycled, or recyclable materials.

Within this step, the last goal is to reduce the negative impact on the environment, with the focus on reducing the level of pollution. On the basis of our findings, we can claim that 105 respondents indicated that they always or often consider if the product is environmentally friendly, 80 consider if it reduces the amount of waste, and 69 if it is biodegradable. When attempting to fulfill this goal, an enterprise should seek possibilities of technological development, with the focus on prevention and reduction of the environment pollution. In this phase, it is essential to realize that at the beginning of the process of designing a new product, there is little information about it, and therefore an enterprise has more freedom in making decisions. This is also due to the costs related to product development being low in this phase. In the final phases of product development, the enterprise has sufficient information about the product, but at the same time there are less possibilities to change its design, because this would appear rather costly for the enterprise, argue by Luttropp \& Lagerstedt (2006).

The next step is to carry out the proposed processes, where the output is the green product. The main goal of this step if to achieve environmental efficiency of products, and placement of green products in the market. It is necessary to implement monitoring of the environmental efficiency of products in each phase of their life cycle, as well as to plan further improvement of these products, on the basis of the obtained results. It has been found out that customers are insufficiently informed about green products, which also affects their purchasing decisions, argue by Musova et al. (2016), Mala et al. (2017), Tweeneboah \& Braimah (2011), and Tanner \& Kast (2003). When placing products in the market, it is essential to focus on making information about our green products available to customers, so they could make the right decision. A frequently marked reason why customers do not buy green products was the lack of information about them. This barrier appears to be the second biggest one, after the high price of green products, and can be removed by providing customers with such information that emphasizes the advantages of purchasing green products (e.g. through integrating a green message into a product, or obtaining green certificates), according to Minarova et al. (2016). It is further necessary to determine the right price of the green product so that it could compete with common products. When providing information to customers, it must be highlighted that a green product saves finances when being used, not forgetting about emphasizing the close link between the environmental and functional characteristics of a product. An enterprise should focus on these aspects as early as at proposing green product innovations e.g. by securing cooperation between the individual departments during product development. If the development of green products is viewed as a chain of several activities which must be performed, we assume that it is essential to harmonize the knowledge, expertise, and skills of those who are responsible for these processes, so as to eliminate all problems related to the environment. It is important that customers realize that by purchasing green products they can contribute to improving the quality of the environment, argue by Abdul-Muhmin (2007). 
The last step is the evaluation of a green product. Environmental evaluation of a life cycle is an approach which investigates the environmental aspects and effects a product has on the environment during its life cycle, from obtaining the resources, through production and implementation to waste disposal, argue by Musa et al. (2016). An enterprise should be aware of its efficiency in the environmental field, so as to assess the impact of its activities and products on the environment. At the same time, the evaluation is a feedback tool, when an enterprise may use the obtained information about development of the individual indicators to plan the improvement of the evaluated processes and products towards the reduction of their negative impacts, or towards encouraging their positive impacts on the environment. This step ensures sustainable improvement of both the product and the processes in an enterprise in relation to the environment.

\section{Conclusion}

Protecting the ecosystem by waste reduction and reduction of the use of natural resources and energy provides numerous entrepreneurial opportunities for innovations. These innovations should lead to creating such products and services which fulfill the requirements of customers, and at the same time their production does not harm the environment.

Based on the results of our research, we may claim that the perception of a green product by customers is mainly related to its positive impact on the environment. Recyclability of a product is perceived as its inseparable part. It was interesting to find out that more than $3 / 4$ of Slovaks agree with the statement that 'it is necessary to offer green products'. Most frequent reasons to buy green products were their positive impact on the customers' health, high quality, and good feeling. Clearly, the most frequently indicated reason for not buying green products by respondents is their high price. The research has found out that the most frequently purchased green products are those from local farmers, and from ecological breeds. The least frequently bought green products are those with ecological packaging.

To achieve the improvement of the state of the environment, as well as the reduction of the negative impact of civilization on the environment is not possible without the participation of business subjects. The offer of green products motivates customers to consumption without feeling guilty, and at the same time ensures sustainable development. Such concept is perceived positively by both the enterprises and the ecologists. Small and medium enterprises should place emphasis on responsible approach to the environment, and long-term effort to make their operations sustainable, which can be achieved by implementing the activities of green logistics, as well as providing green products.

\section{Acknowledgment}

This paper is an output of the science projects VEGA No. 1/0934/16 and No. 1/0010/17 as a result of a research.

\section{References}

Abdul-Muhmin, A.G. (2007). Exploring Consumers' Willingness to be Environmentally Friendly. International Journal of Consumer Studies, 31, 237-247.

Chan, T. \& Wong, CH. (2012). The Consumption Side of Sustainable Fashion Supply Chain: Understanding Fashion Consumer Eco-Fashion Consumption Decision. Journal of Fashion Marketing and Management: An International Journal, 16(2), 193-215.

Chen, Y.S., Lai, S.B. \& Wen, C.T. (2006). The Influence of Green Innovation Performance on Corporate Advantage in Taiwan. Journal of Business Ethics, 67 (4), 331-339. 
Chen, J. \& Lobo, A. (2012). Organic Food Products in China: Determinants of Consumers` Purchase Intentions. The International Review of Retail, Distribution and Consumer Research, 22(3), 293-314.

Dangelico, R.M. \& Pontrandolfo, P. (2010). From Green Product Definitions and Classifications to the Green Option Matrix. Journal of Cleaner Production, 18(16), 1608-1628.

Dangelico, R.M. \& Pujari, D. (2010). Mainstreaming Green Product Innovation: Why and How Companies Integrate Environmental Sustainability. Journal of Business Ethics, 95, 471-486.

Eze, U.C. \& Ndubisi, N.O. (2013). Green Buyer Behavior: Evidence from Asia Consumers. Journal of Asian and African Studies, 48(4), 413-426.

Faletar, J., Jelacic, D. et al. (2016). Motivating Employees in Wood Processing Company Before and After Restructuring. BioResources, 11 (1), 2504-2515.

Fraj-Andres, E. \& Martinez-Salinas, E. (2007). Impact of Environmental Knowledge on Ecological Consumer Behaviour: An Empirical Analysis. Journal of International Consumer Marketing, 19(3), 73-102.

Gadenne, D. et al. (2013). The Influence of Consumers`Environmental Beliefs and Attitudes on Energy Saving Behaviours. Energy Policy, 39(12), 7684-7694.

Hajduchova, I., et al. (2016). The Slovakian Forest-Based Sector in The Context of Globalization. BioResources, 11(2), 4808-4820.

Hanssen, O.J. (1999). Sustainable Product Systems-Experiences Based on Case Projects in Sustainable Product Development. Journal of Cleaner Production, 7(1), 27-41.

Kaebernick, H. \& Soriano, V. (2000). An Approach to Simplified Environmental Assessment by Classification of Products. Proceedings of the 7th International Seminar on Life Cycle Engineering. Tokyo, Japan: 163 169.

Klementova, J., Sedliacikova, M. \& Moresova, M. (2016). Custom Manufacturing of Furniture in The Context of Globalization and Quality Management. Proceedings of $16^{\text {th }}$ International Scientific Conference on Globalization and its Socio-Economic Consequences. Rajecke Teplice, Slovakia: 905-913.

Lanzavecchia, C. (2004). Il fare ecologico. Il prodotto industrial e I suoi requisity ambientali. Turin, Italy: Time and Minf Press.

Luttrop, C. \& Lagerstedt, J. (2006). EcoDesign and The Ten Golden Rules: Generic Advice for Merging Environmental Aspects into Product Development. Journal of Cleaner Production, 14(15-16), 1396-1408.

Mala, D. et al. (2017). Green Logistics in The Context of Sustainable Development in Small and Medium Enterprises. Drvna Industrija, 68(1), 69-79.

Mala, D. \& Musova, Z. (2015). Perception of Implementation Processes of Green Logistics in SMEs in Slovakia. Proceedings of $4^{\text {th }}$ World Conference on Business, Economics and Management. Ephesus, Turkey: 139-143.

Miles, M.P. \& Covin, J.G. (2000). Environmental Marketing: A Source of Reputational Competitive and Financial Advantage. Journal of Business Ethics, 23(3), 299-311.

Minarova, M., Musova, Z. \& Bencikova, D. (2016). Eco-labels and Consumer. Proceedings of International Scientific Conference on Marketing Identity 2016. Smolenice, Slovakia: 199-208.

Musa, H., Musova, Z. \& Huliakova, Z. (2016). Innovative Approaches in a Socially Responsible Marketing in a Global Environment. Proceedings of $16^{\text {th }}$ International Scientific Conference on Globalization and its SocioEconomic Consequences. Rajecke Teplice, Slovakia: 1466-1473.

Ottman, J.A., Stafford, E.E. \& Hartman, C.L. (2006). Avoiding Green Marketing Myopia: Ways to Improve Consumer Appeal for Environmentally Preferable Products. Journal Environment: Science and Policy for Sustainable Development, 48(5), 22-36.

Peattie, K. (1995). Environmental Marketing Management: Meeting the Green Challenge. London, United Kingdom: Pitman Publishing Company.

Polonsky, M.J. \& Ottman, J. (1998). Stakeholders`Contribution to the Green New Product Development Process. Journal of Marketing Management, 14, 533-557.

Pujari, D., Wright, G. \& Paettie, K. (2003). Green and Competitive. Influences on Environmental New Product Development Performance. Journal of Business Research, 56(8), 657-671.

Rosa, M.D. \& Devashish, P. (2010). Mainstreaming Green Product Innovation: Why and How Companies Integrate Environmental Sustainability. Journal of Business Ethics, 95(3), 471-486.

Roy, R. et al. (1993). Case Studies of Creativity in Innovative Product Development. Design Studies, 14(4), 423443.

Salazar, H., Oerlemans, L. \& Van Stroe-Biezen, S. (2013). Social Influence on Sustainable Consumption: Evidence from a Behavioural Experiment. International Journal Osconsumer Studies, 37(2), 172-180.

Sedliacikova, M. et al. (2016). Improving the Performance of Small and Medium Wood-Processing Enterprises. BioResources, 11(1), 439-450.

Shrivastava, P. (1995). Environmental Technologies and Competitive Advantage. Strategic Management Journal, 16, 183-200. 
Smith, S. \& Paladino, A. (2010). Eating Clean and Green? Investigating Consumer Motivations Towards the Purchase of Organic Food. Australasian Marketing Journal. 18(2), 93-104.

Sousa, I. \& Wallace, D. (2006). Product Classification to Support Approximate Life Cycle Assessment of Design Concepts. Technological Forecasting and Social Change, 73(3), 228-249.

Tanner, C. \& Kast, W. (2003). Promoting Sustainable Consumption: Determinants of Green Purchases by Swiss Consumers. Psychology \& Marketing, 20(10), 883-902.

Tweeneboah, E. \& Braimah, M. (2011). An Exploratory Study of The Impact of Green Brand Awareness on Consumer Purchase Decisions in Ghana. Journal of Marketing Development and Competitiveness, 5(7), 1118.

Unruh, G. \& Etterson, R. (2010). Growing Green. Harvard Business Review, 88, 94-100.

Welsch, H. \& Kuhling, J. (2009). Determinants of Pro-environmental Consumption: The Role of Reference Groups and Routine Behavior. Ecological Economics, 69(1), 166-176. 